\title{
NO PÔR DO SOL, A CIGARRA VOA RETO, 2020.
}

Al atardecer, la cigarra vuela recta, 2020.

At sunset, the cicada flies straight, 2020.

$>$ Wilka Sales [Universidade Federal do Pará, Brasil]*

Citação recomendada:
SALES, Wilka. No pôr
do sol, a cigarra voa
reto, 2020 . Revista
Poiésis, Niterói, v. 22 ,
n. 38, p. 141-150, jul./
dez. 2021 . [https://doi.
org/ $10.22409 /$ poiesis.
v22i38.45687]
Este documento é
distribuido nos termos da
licença Creative Com-
mons Atribuição-Não-
Comercial 4.0 Internacio-
nal [CC-BY-NC] C 2021
Wilka Sales.

(Submetido: 31/8/2020; Aceito: $7 / 1 / 2021$

Publicado: 7/7/2021)
No pôr do sol, a cigarra voa reto, 2020

[ensaio/experimento, poiéticas/poéticas, foto performance,/vídeoperformance]

Este ensaio/experimento surge a partir de inquietações e investigações sobre o meu projeto de pesquisa em Poéticas Visuais [2019] ampliando o campo de experimentações com a performance e seus desdobramentos e de que modo é possível identificar diálogos e cruzamentos entre corpo, memória e lugar na foto performance e vídeo performance, aplicando a intuição como método e destacando a relação com o passado, com a dimensão de experiência, com o corpo e com a imaginação.

Construindo uma liberdade intuitiva e experimental, vou criando auto-narrativas enviesadas entre passado -futuro, tempo/lugar afetivos e simbólicos, onde ocorrem os processos de criação das poéticas, através de experiências adquiridas com minha mãe e avó.

Observando o mundo delas, que também é o meu, vou apresentando fragmentos de leituras da natureza, fenômenos físicos, rastros de memória genealógica, num deslocamento, como propõe Paul Virilio, uma "telepresença distante, para além das aparências sensiveis". Para além das memórias imateriais, rituais diários, utilizo, ainda, a estrutura material para reconstruir um mundo pessoal, pautadas nas relações estabelecidas entre corpo e objeto.

*Wilka Sales é artista visual, arte-educadora, vive entre Maranhão e Pará, é mestranda pela PPGARTES/ICA/UFPA na linha de pesquisa - Poéticas e Processos em Artes. E-mail: wilkasalesb@gmail.com, ORCID: https://orcid.org/0000-0003-0139-6476 

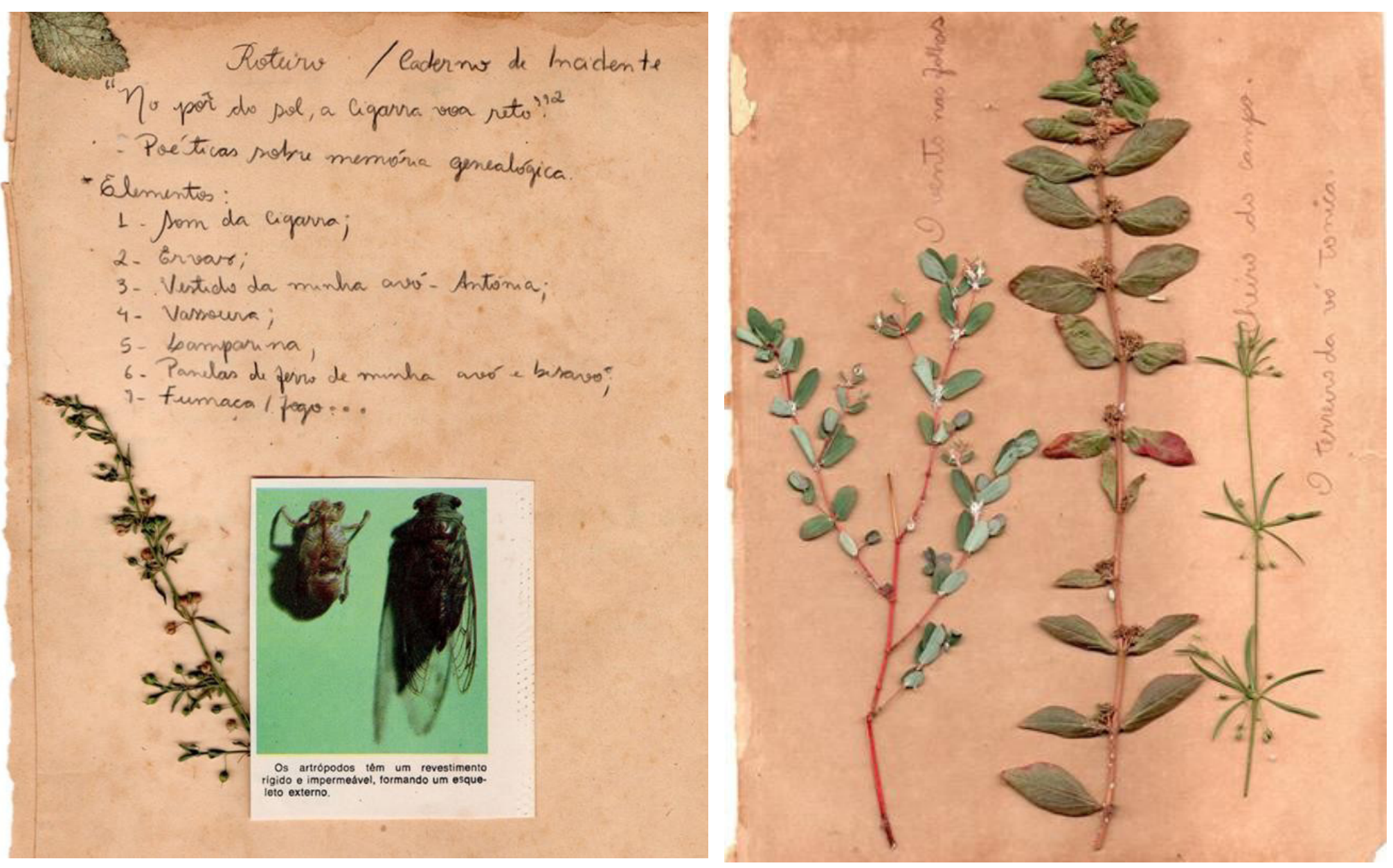
Historicamente, a buica era a partira, a adevisha, benzedeira on a futiceura do vilarepo. (FEDERICI, 2017, P, 362).

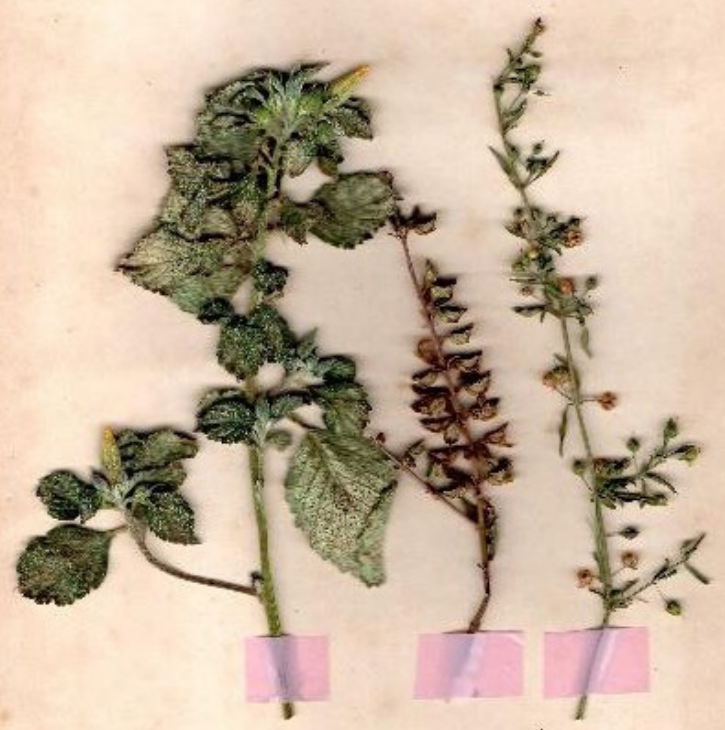

Malva-puloges para limpar e varrer.

Bantios de alfaraca para acalmar Cipó de varsourum ha para benzer

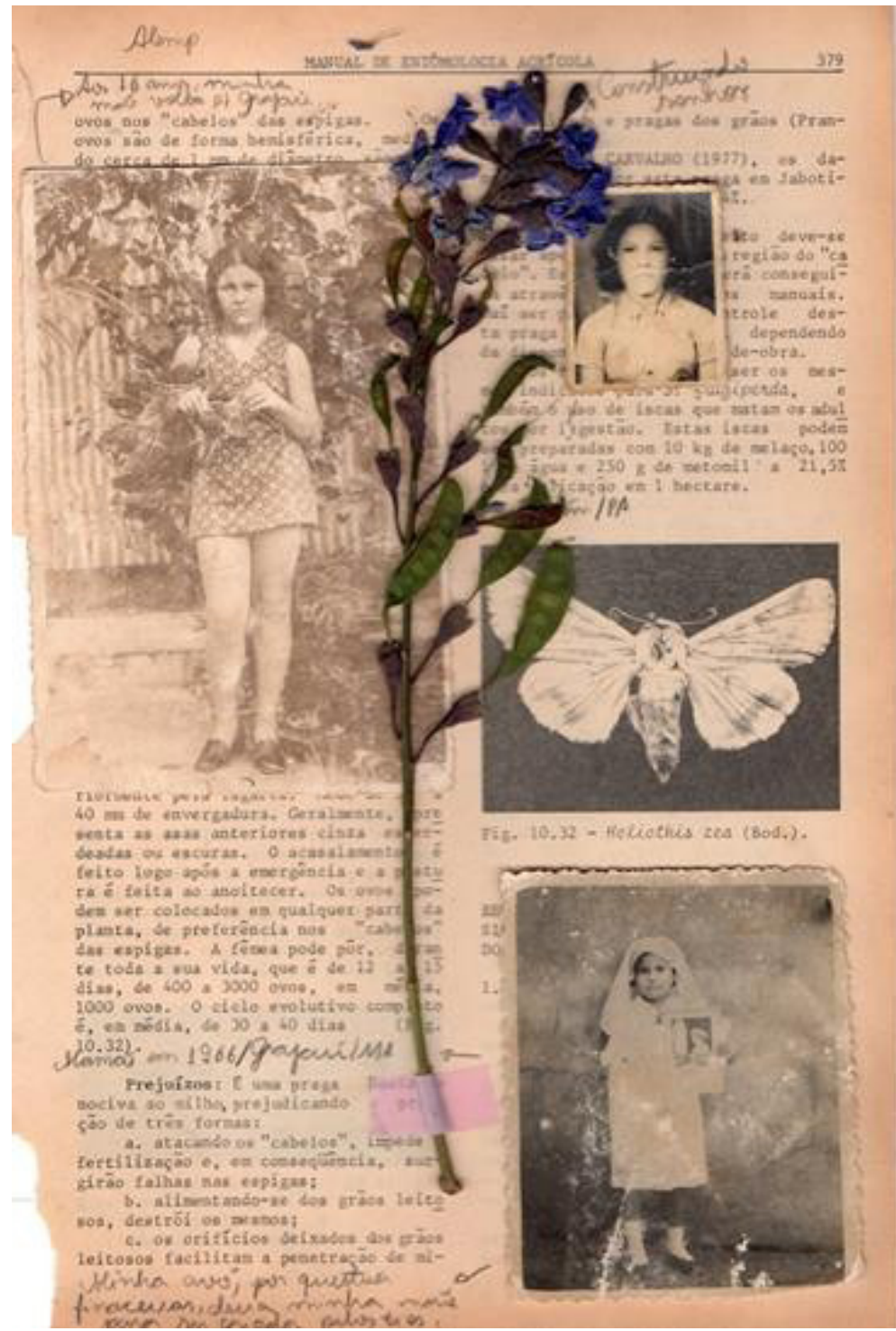



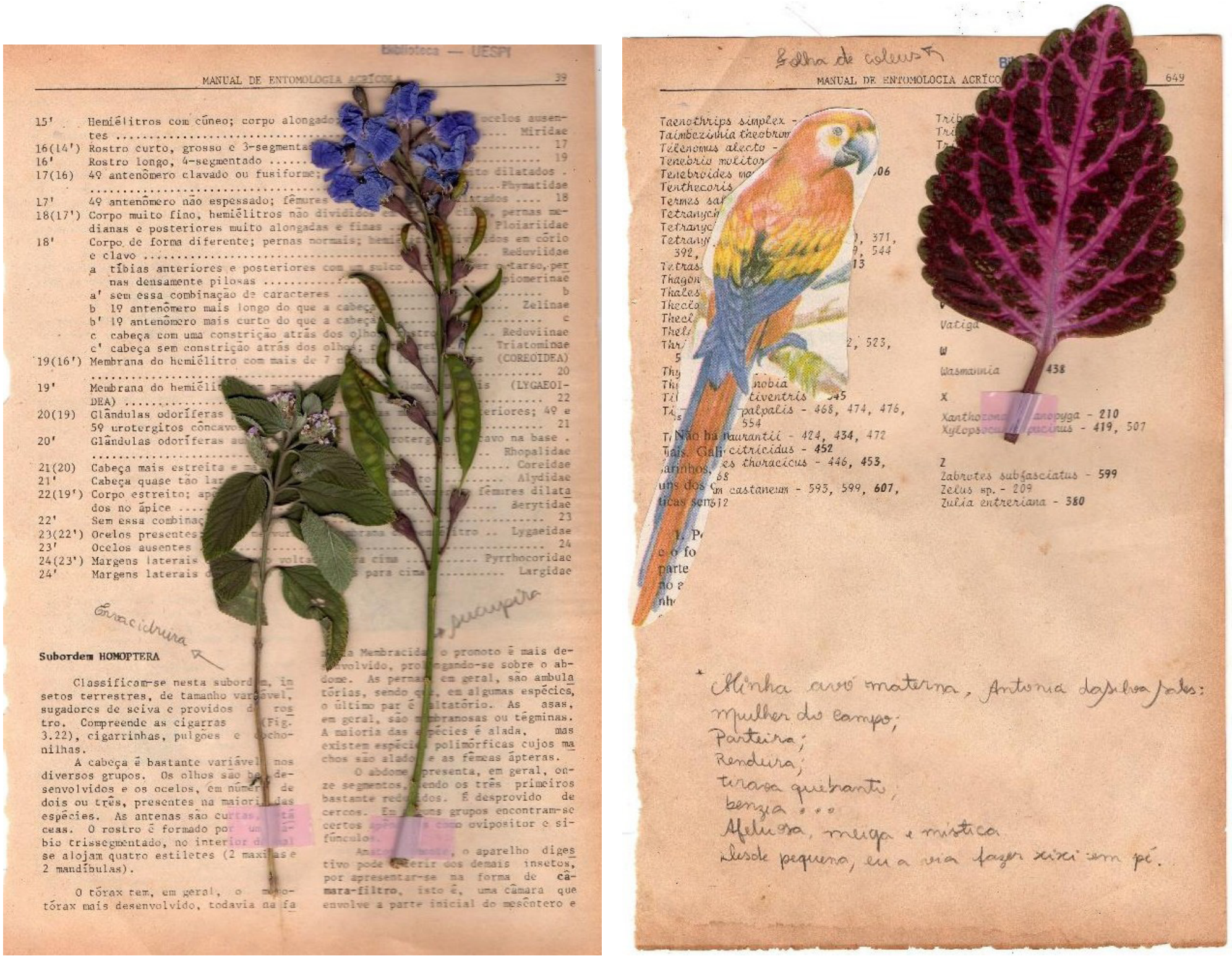


\section{MUNUAL ISE KNTONDLOCIA ACRICOLA}

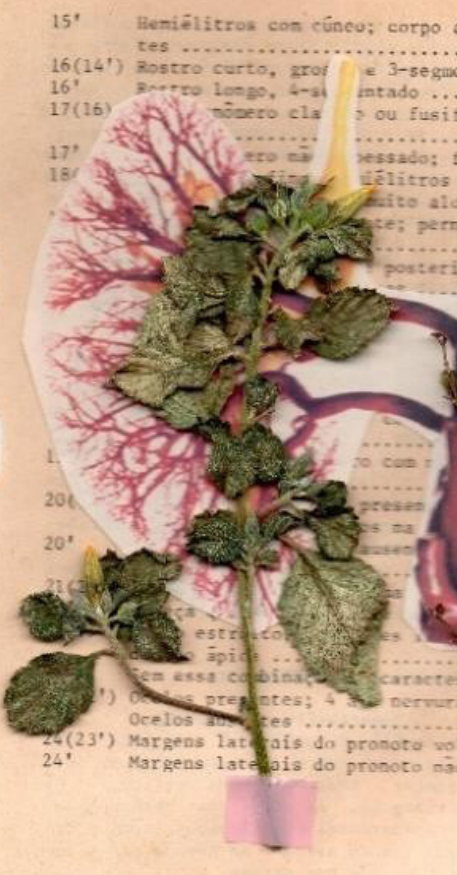

\section{Subordem HOMOPTERA}

Classificanse nesta subordem, in setos terrestres, de tamanho variavel, sugadores de seiva e providos de ros tro. Compreende as cigarras (Fig.
3.22), cigarriahas, pulgoes a cochonilhas.

$\Delta$ cabeça é bastante variávei nos diversos grupos. Os nthos sajo bes desenvolvidos e os ocelos. po púpero de dois ou trûs, prescntes na naioria das espéties. As sntenas săo curtos, sot. ceas. O rostro e formado por un labio triseegacntado, no itretrior do cuas se alojat quatro estiletes (2 maxilase 2 nandíbulos).

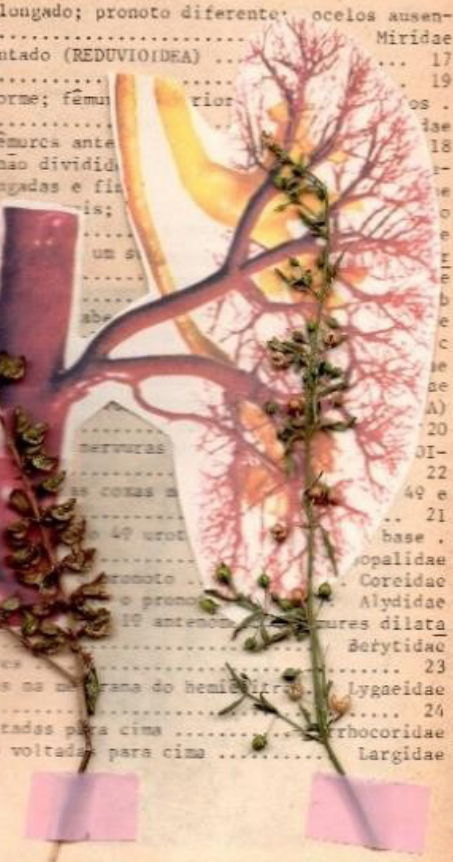

milia Metbracidae o pronoto a mais desenvolvido, prolongando-se sobre a abdonc. As pernas, ent geral, säo ambula törixs, sendo que, em al pumes expécies. o último par é saltatörio. As asas. em gèral, são memilanosas ou tégninas. $\Lambda$ maioria das espécies é alada, tas. existem espécies polimórficas cujos ma chos кйо alados e as fêtreas ápteras.

0 abdome apresents, em ceral, onze segmentos, sendo os tres prínciro bastante reduzidos. L dusprovido de cerens. Em alguns grupos encontracrse fünculos.

Anatoricaciente, a aparelbo diges tivo pode diferir dos derais insetoy, por apresentar-se na furma de câmara-filtro, isto é, uma cänara que certos apendices como ovipositor a si-

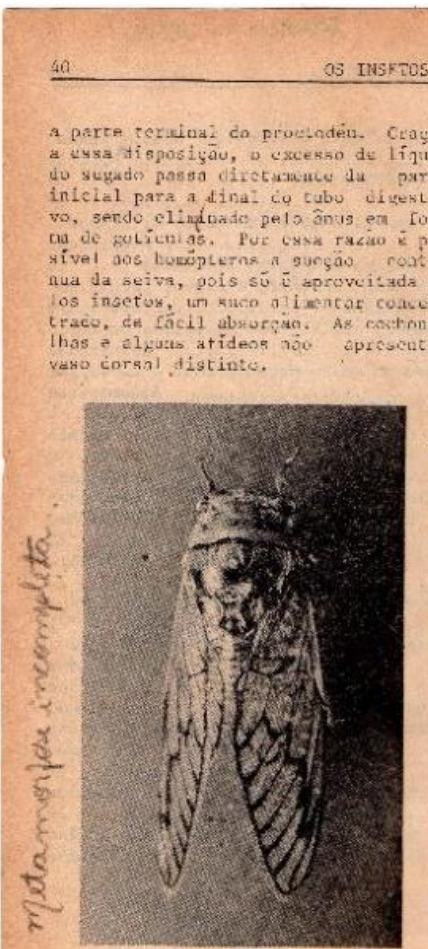

His. 3.22 - ordell Usciplera-Homoptera.

F.s quase torlos os Luxópleros, $p$ rin cipalnetie as furnas jowens, aprescu-

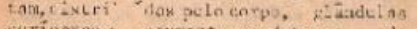
ceripazal t. -eguiroto pestutacas de Lika blorecin reved sjuncante e ne aspecto puiveruiento. Eua alramas esjêcick pode-se cazorrar af xlu, stûidulab secretoras dic kech o ce ack. Os ioxiopteros teptoiluzcia oc, en

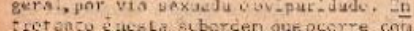
maíor frect पiencic a pirrenogenese. A

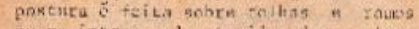
us antertue dos tecilos dax plantas. Os owor sán simples nit provides

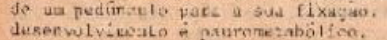

Seadu iasetas rerrestres e tilốta gos, sligara a seiva das partes tertas gaizek das glantas. Dai a sua caurca retoo cousalus pola succio cunstane de

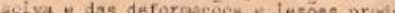
cidas nes plaulas os bonopteros pole cor vetores de roencas de virus, pos de introduciret subgeânciux töxicas nge plantas.

A suborden Homptera contes con cerce de 35,000 expécies descritas, di Lribuidas en 3 diviuöes, nendo as mais inport untes:

- divis of aDCaENorkнrscäa: Compreen L- os howptye fon o roatro enecrgia da part-intior da cabeca, coul en fox curtas = of áceas. As torf

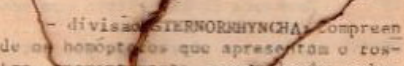

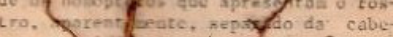
$\mathrm{ca}$, cole tenas de

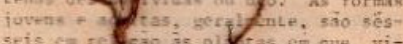
seis cerof cas as pi f tas en que vi-

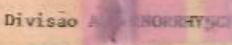

Supertamilia crcandibea

fauilia Cirodidae: $\mathrm{A}$ a tamilia da elgarras, que se corecteriza, por apro sentar trêx devlos no verticc, et trlangula. As asas yas menbrciuses, transpareatcs ou colorides; tên o organo sonoto situado no obdume, mair deप्रतuvolvida nos uectros. As cigarras adultas sugae os raa ferugat a portire eadofiricumetile. Dos uves nascen de nintas gue se aprof unCara ao solo para sugarca as raizes. Ns Pat de pazass que é do tipo fosserial. 20, poremo dhrar vairios aoue. Ax expe

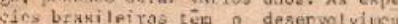
to curapicto 30 redor do vir ane pzintipais espécies sne: nuesailh gir

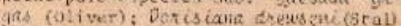
- Cariveta jascicalota (Gerrar) Todos

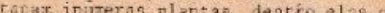
taceiro.

Hajicinada seoterdecir (L.) E tha especic uturinoaa que apresent a do anos. 


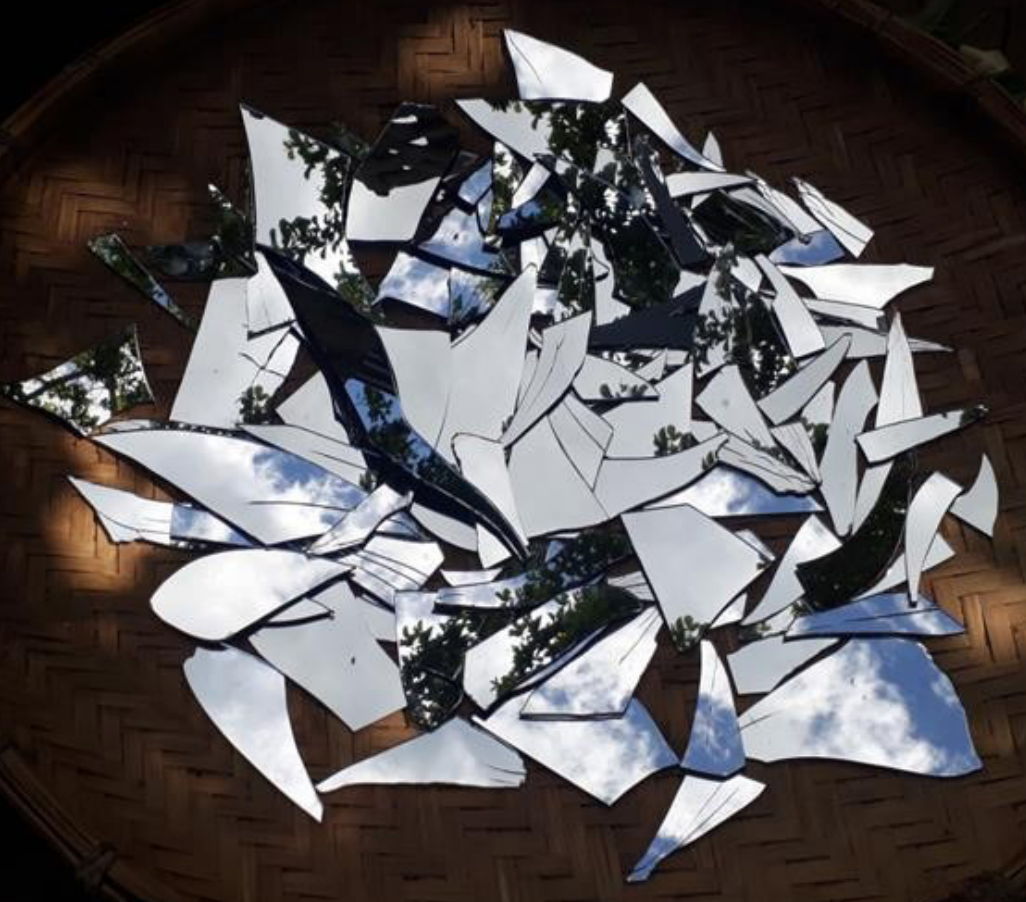




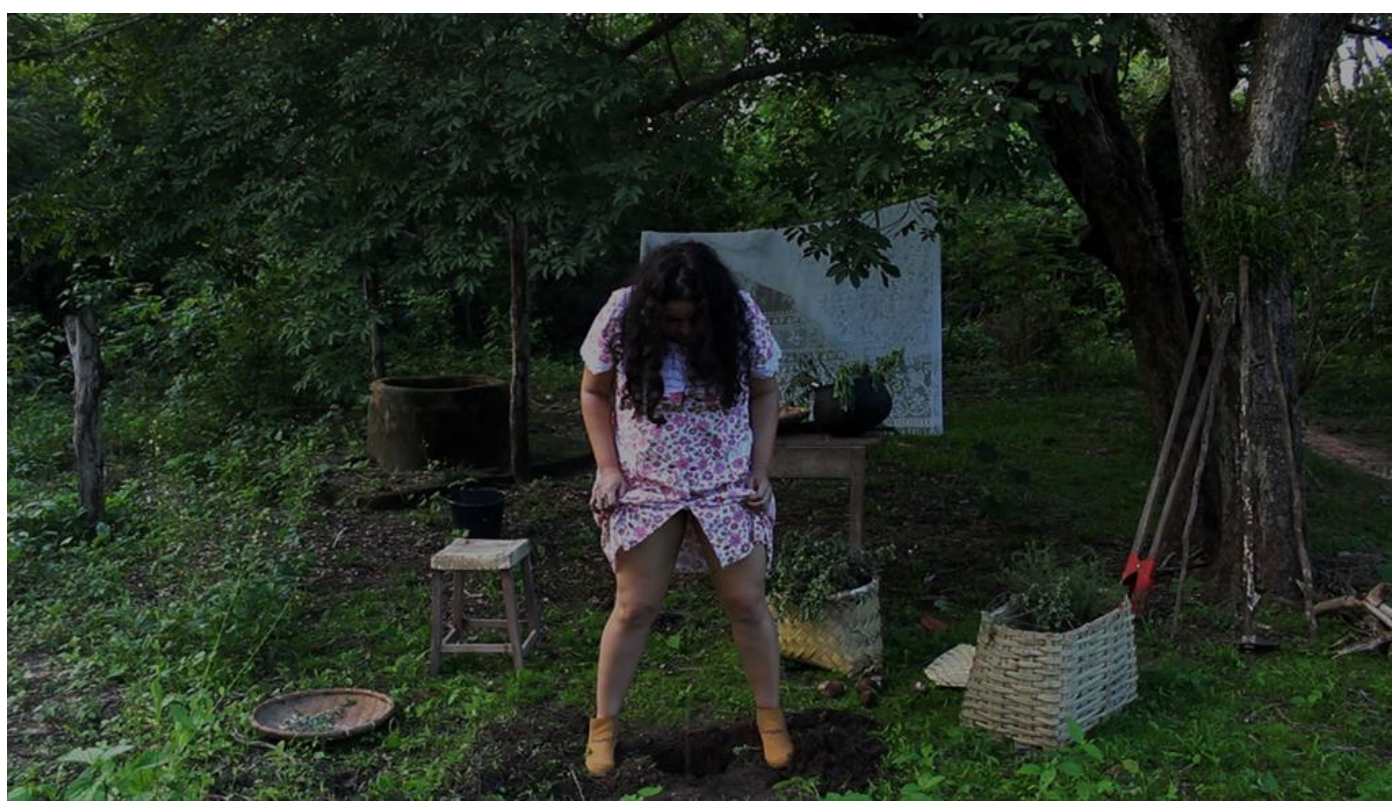

Rituais diários, técnica/ato de fazer xixi em pé, vídeo performance, 2019.

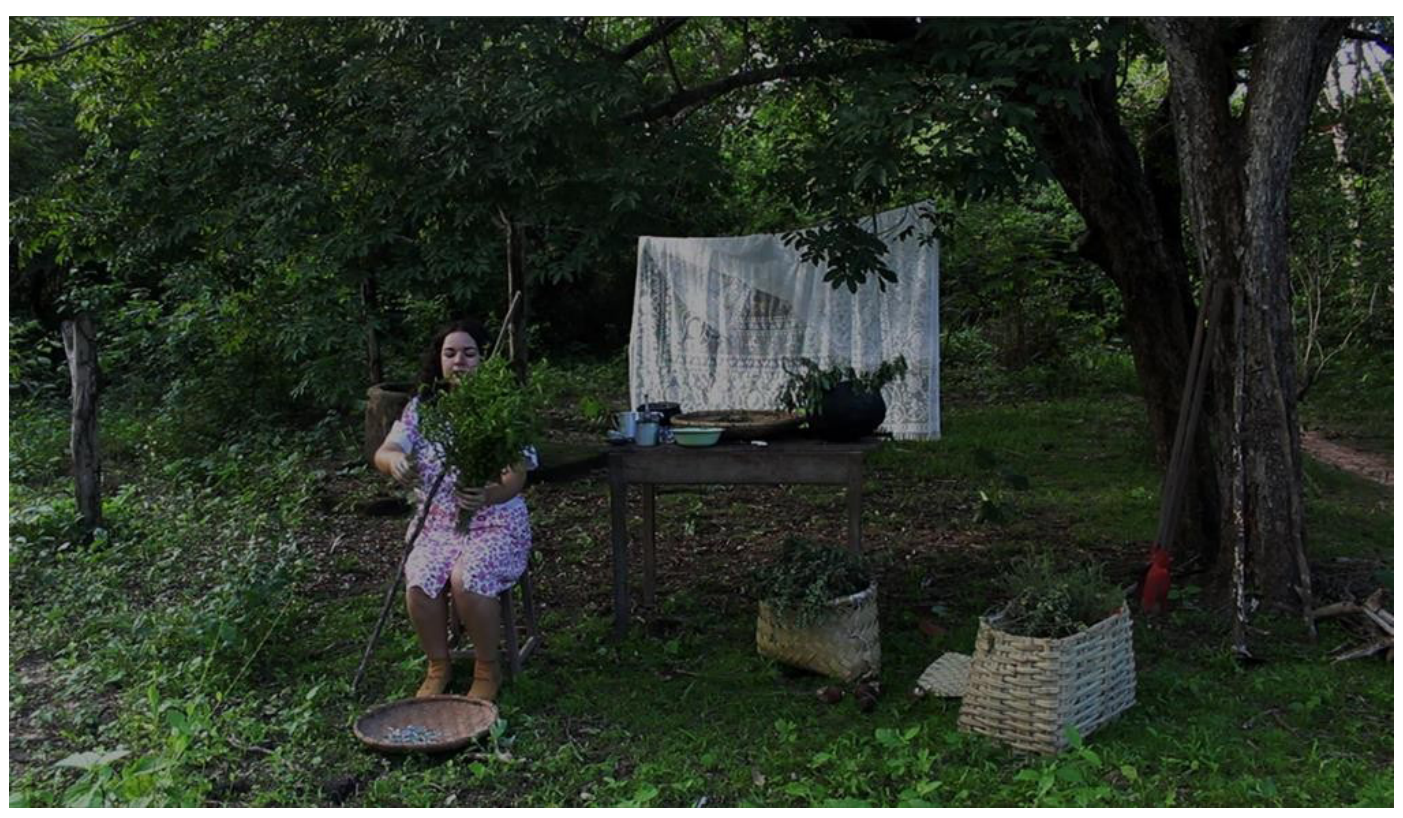

A vassoura exerce a mística da limpeza. Vó Tonica fazia suas próprias vassouras, vídeo performance, 2019. 


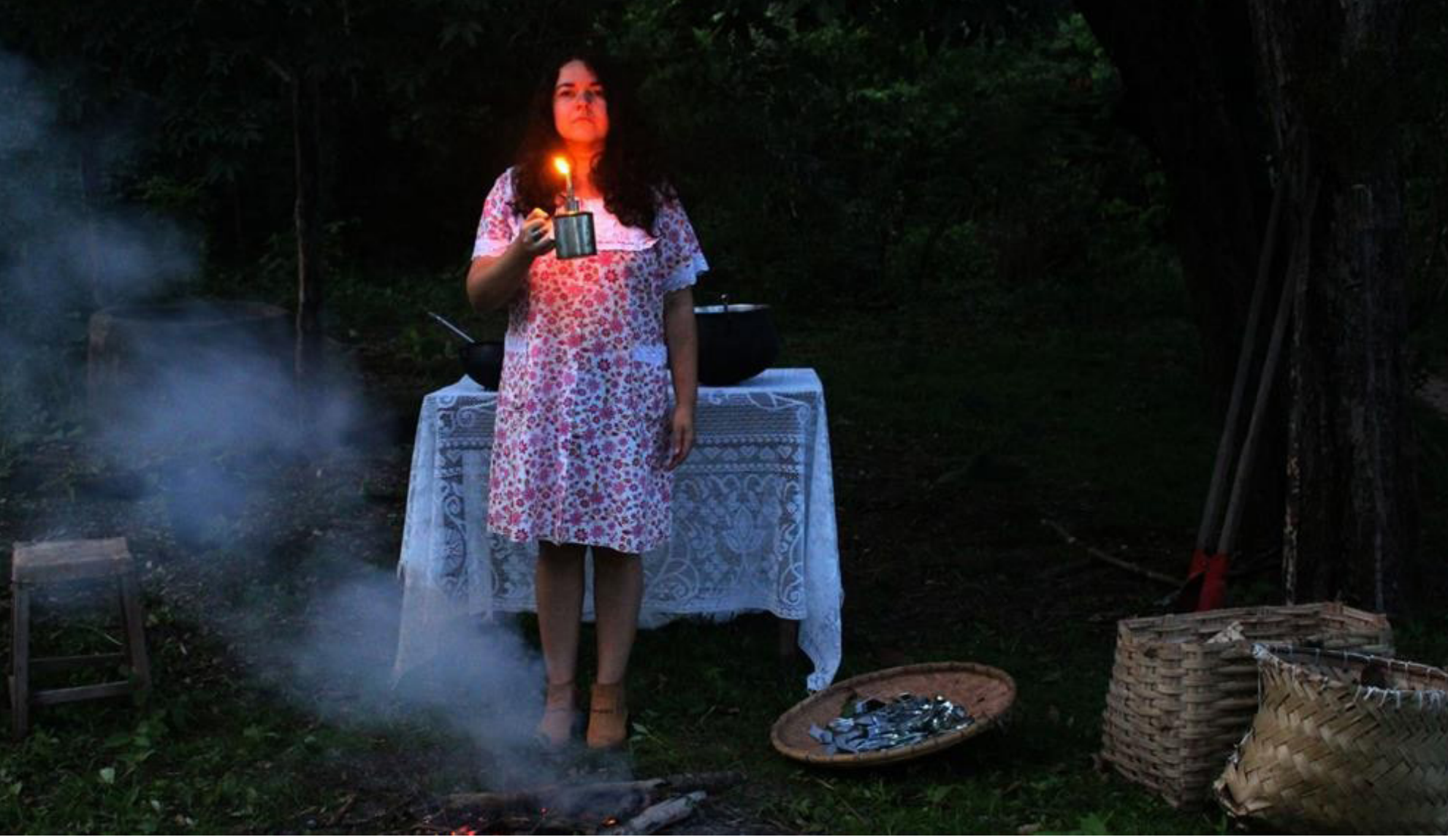

O vento na lamparina, vídeo performance, 2019.

Na casa de minha avó até o final da década de 90, não tinha energia elétrica, Luz da lamparina, velas e lampiões, iluminavam os caminhos, dentro e fora. Foto performance, 2020.

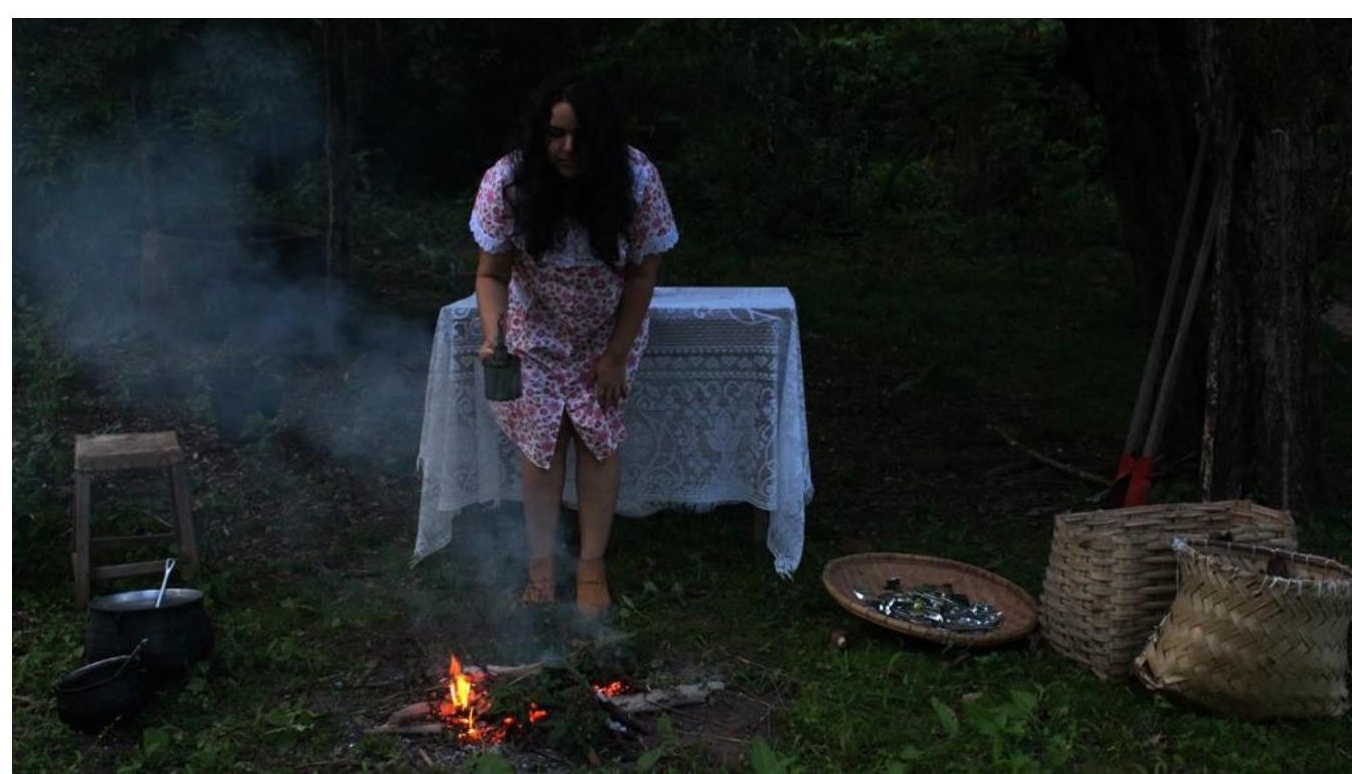




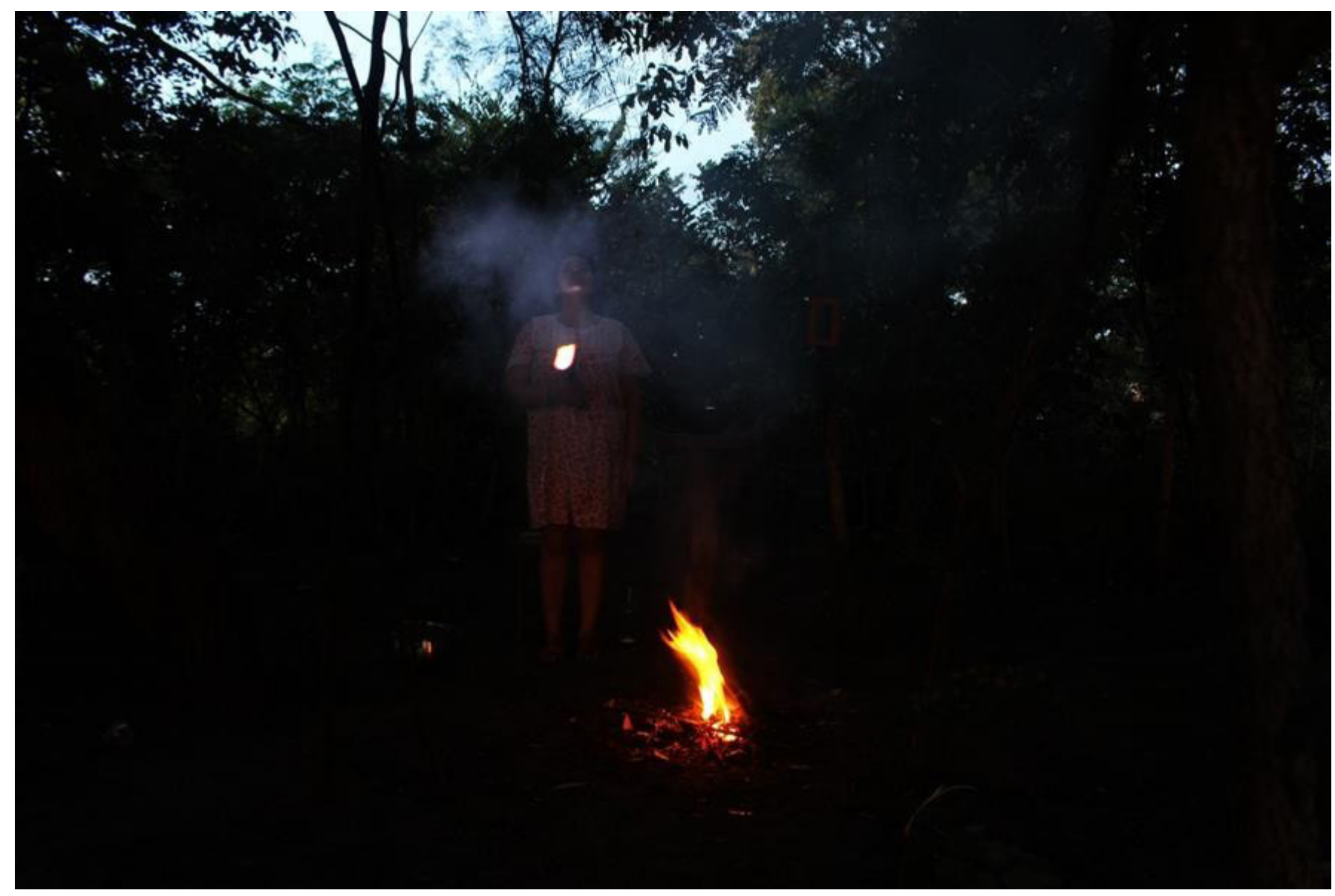

Na boca da noite, no pôr do sol, o som da cigarra, foto performance, 2020. 


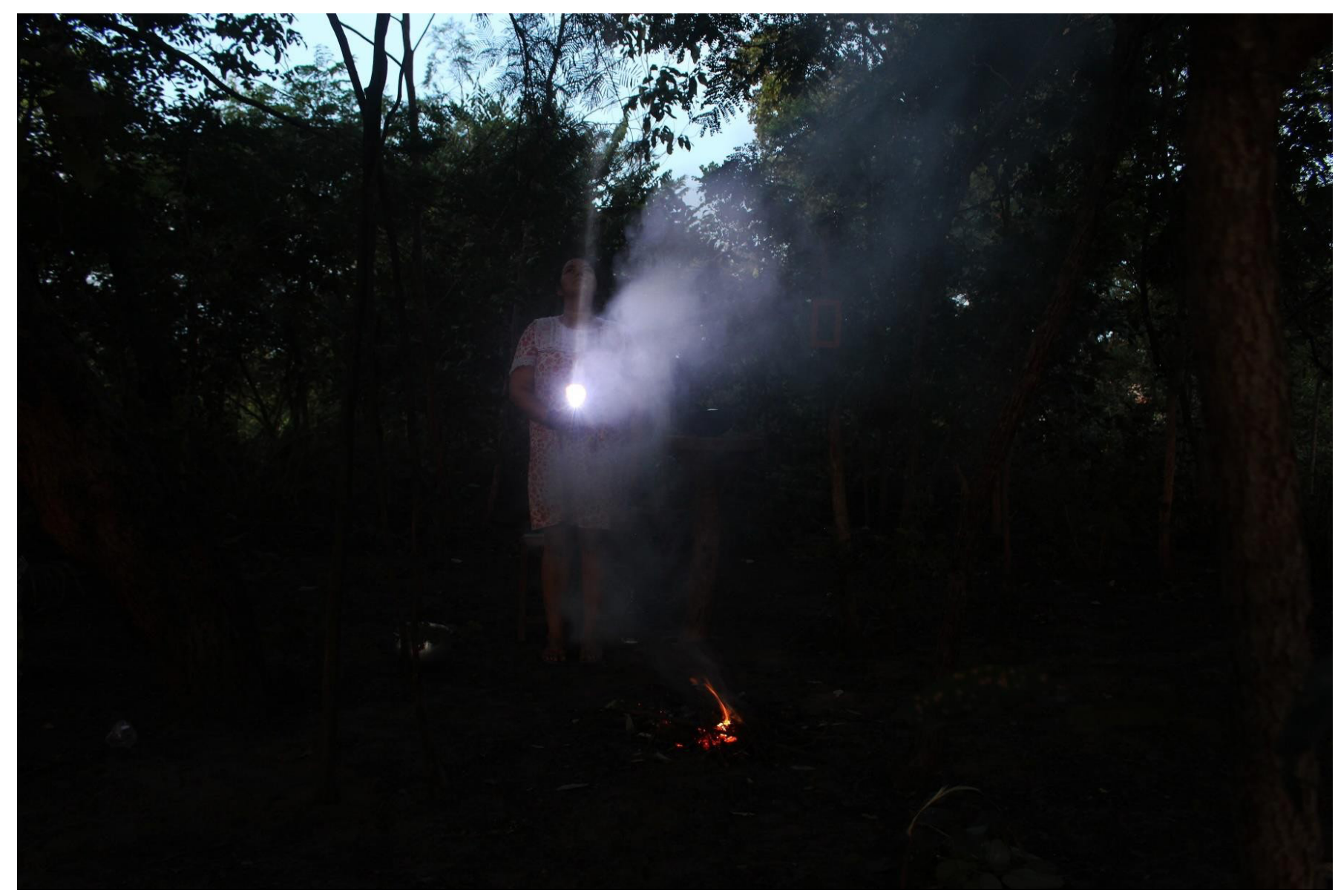

O som da cigarra me faz lembrar de minhas origens, foto performance, 2020 


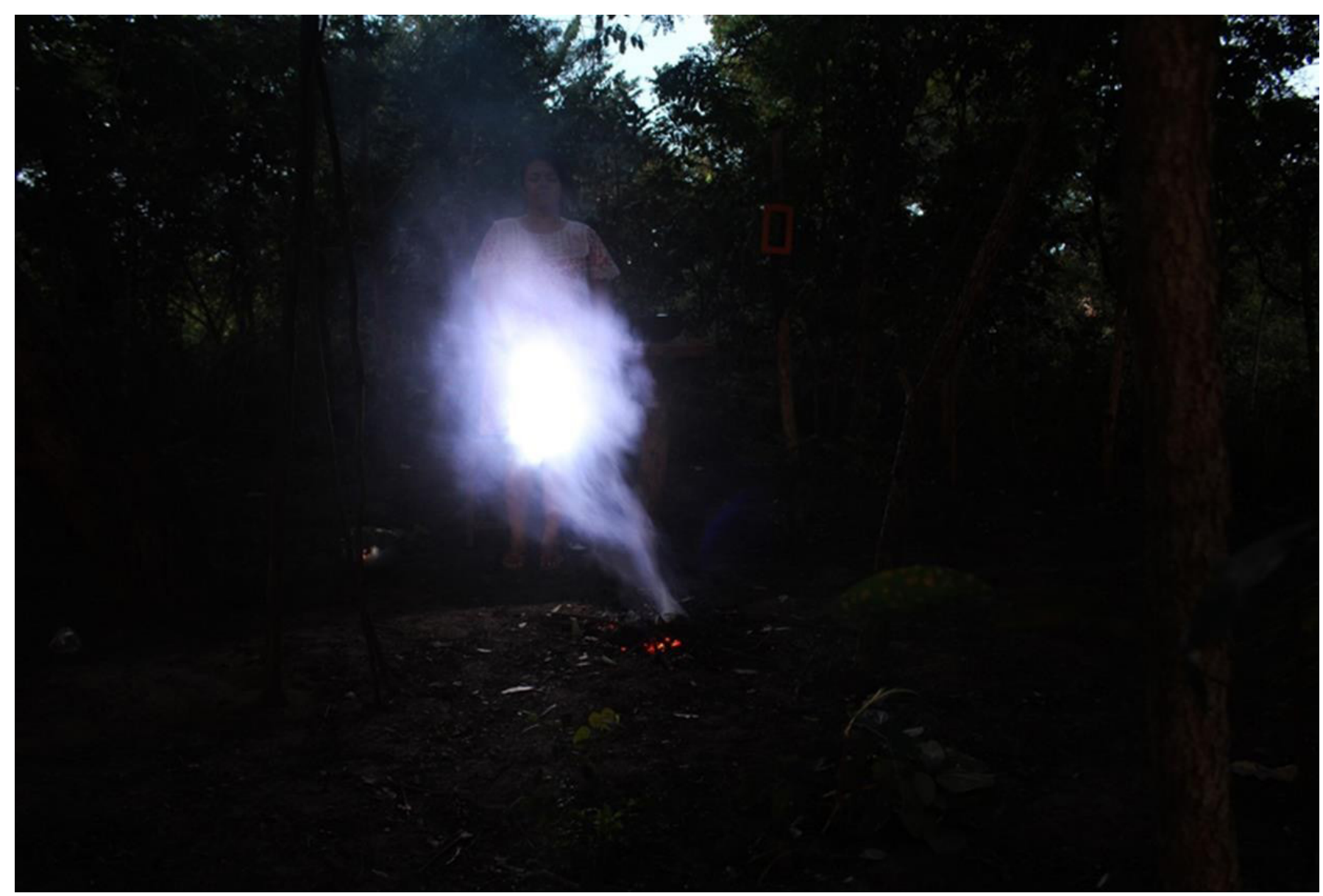

A fumaça, uma névoa do esquecimento que reaparece, foto performance 2020. 